\title{
CDISC SEND Rad/Nuc Targeted Injury Model Response Terminology
}

National Cancer Institute

\section{Source}

National Cancer Institute. CDISC SEND Rad/NuC Targeted Injury Model Response

Terminology. NCI Thesaurus. Code C160928.

Terminology associated with the rad/nuc targeted injury model response codelist of the Clinical Data Interchange Standards Consortium (CDISC) Standard for the Exchange of Non-clinical Data (SEND). 